\title{
Cryotherapy - A call for further research
}

\section{Authors:}

Jeremy R. Hawkins ${ }^{1}$, PhD, ATC

Michael Reeder ${ }^{2}$, DO

Kristin J. Heumann ${ }^{3}$, PhD, CSCS, c-EP

\section{Affiliations:}

${ }^{1}$ Colorado Mesa University

E-mail: jrhawkins@coloradomesa.edu

${ }^{2}$ Colorado Mesa University

E-mail: mreeder@coloradomesa.edu

${ }^{3}$ Colorado Mesa University

E-mail:kheumann@coloradomesa.edu

\section{Correspondence author:}

Jeremy R. Hawkins

E-mail: jrhawkins@ coloradomesa.edu

\begin{abstract}
Cryotherapy is a common component of acute and sub-acute therapy in certain settings, but the use of cryotherapy is controversial and not well understood. The theory for cryotherapy use in an acute setting centers on decreasing secondary injury and thus total tissue damage. Opponents of this therapy cite a lack of evidence to support the use of cryotherapy and that cryotherapy delays the inflammatory processes. Neither argument has conclusive evidence to support their claims. The data to substantiate or refute the use of cryotherapy exists in the various settings that use cryotherapy on a daily basis and needs to be collected, analyzed, and discussed.
\end{abstract}

Keywords: ice, best practice, injury management 


\section{Introduction/Background}

Cryotherapy, the therapeutic application of ice, is a common treatment for acute and non-acute orthopedic injuries. The mnemonics of RICE (rest, ice, compression, elevation), PRICE (protection, rest, ice, compression, elevation), and/or POLICE (protection, optimal loading, ice, compression, elevation) have been taught as a guide for the treatment of these conditions, with ice prominently found in each one. Interestingly, there is little evidence to support the use of ice for musculoskeletal injuries. The following discussion will outline the theoretical basis for the use of cryotherapy, including the existing data for cryotherapy application, discuss the growing evidence against cryotherapy use, and will conclude with how the entire issue may be resolved.

\section{Theoretical Basis for Cryotherapy} Use

Inflammation is "a local response to cellular injury that is marked by capillary dilation, leukocyte infiltration, redness, heat, and pain that serves as a mechanism initiating the elimination of noxious agents and of damaged tissue." 1 Knight connected this naturally occurring process to acute orthopedic injury in 1976 with the development of the Sport Injury Model. ${ }^{2}$ The Sport Injury Model includes eight overlapping phases that begin with an injury and end with phagocytosis, the body removing and repairing the damaged tissues. ${ }^{3}$ Knight theorized that cryotherapy applied while the body is going through the inflammatory process helps decrease the additional damage to the area that results from the inflammatory process, something referred to collectively as secondary injury. Specifically, by decreasing the metabolic needs of the surrounding tissues that might have compromised oxygen supply, these tissues can continue to function until their oxygen supply is restored. Theoretically, this results in less total tissue damage. A few studies support this claim, most notably the work by Merrick, et al. in 1999. ${ }^{4}$ In this study using rats as a population, damage akin to musculoskeletal injury was induced and subsequently treated with cryotherapy. The authors noted a decrease in oxidative function as measured by the reduction of triphenyltetrazolium chloride (TTC) to triphenylformazan (formazan red). This reduction in oxidative function indicated that secondary injury does occur. Further, the prolonged use of cryotherapy (5 hours) retarded the amount of secondary injury.

With the premise behind the acute orthopedic injury use of cryotherapy related to a decrease in tissue temperature, much of the cryotherapy research has focused on tissue temperatures. From these studies, the following is evident with the use of ice packs made from crushed ice:

- Crushed ice can be applied directly to the skin ${ }^{5}$

- Chemical gel packs are not safe to apply directly to the skin due to the potential to cause frostbite and therefore must be applied with a barrier between the gel pack and the skin $^{3,6}$

- Using a barrier between a crushed ice pack and the skin decreases the effectiveness of the modality to cool the treatment area ${ }^{7}$

- Adipose tissue thickness should be considered when applying an ice pack, ${ }^{8,9}$ although additional data is needed to determine whether this is solely due to adipose tissue properties or depth of penetration ${ }^{10}$

- Applying ice under an elastic wrap facilitates a decrease in tissue temperature, whereas applying ice 
under plastic wrap does not facilitate the same tissue temperature decrease $\mathrm{e}^{11}$

- Anesthesia can occur in $15-20$ minutes $^{12}$

- The amount of elevation does not affect skin temperature cooling ${ }^{13}$

- The use of a crushed ice pack does not adversely affect muscle or joint function ${ }^{14,15}$

Although proponents feel a decrease in temperature is beneficial to an acute orthopedic injury, how much of a decrease has never been determined.

Having discussed the use of cryotherapy in several settings, it is evident many believe that the benefits of cryotherapy are the same regardless of whether cryotherapy is applied acutely, later in the injury process, or in situations unrelated to orthopedic injury. For example, the use of cryotherapy in between sets of arm pulls ${ }^{16}$ or pull-ups ${ }^{17}$ increases overall performance. Clinicians need to be aware of the specific therapeutic goal they have in mind when using cryotherapy and adjust the approach accordingly. Discussion of guidelines for these adjustments occurs in detail below.

\subsection{Whole Body Cryotherapy}

In recent years, whole body cryotherapy (WBC) has gained in prominence. According to the U.S. Food and Drug Administration, various manufacturers' websites claim that WBC has beneficial effects on "asthma, Alzheimer's, anxiety, chronic pain, depression, fibromyalgia, insomnia, migraines, multiple sclerosis, osteoarthritis, rheumatoid arthritis, and weight loss," as well as can "improve blood circulation, increase metabolism, improve recovery and soreness after workouts, and relieve joint and body pain."18
The FDA asserts there is a lack of evidence for the use of WBC, even pointing out that WBC has not been cleared or approved for medical treatment of any specific medical conditions. However, the evidence for the use of WBC, while limited, is growing. For example, positive results were observed when using $\mathrm{WBC}$ in conjunction with physical therapy in the management of adhesive capsulitis of the shoulder, ${ }^{19}$ an improvement in quality of life of fibromyalgic patients, ${ }^{20}$ and the treatment of exercise induced muscle damage. ${ }^{21}$

\section{Growing Evidence against Cryotherapy Use}

Those who speak in opposition to the use of cryotherapy come from two main positions. The first position concentrates on the idea that cryotherapy slows the natural inflammatory process by decreasing blood flow to the area and the signaling necessary to promote the inflammatory process. A recent article seems to support this claim. Lindsey et al. demonstrated that repetitive cryotherapy decreased $\mathrm{T}$-cell and monocyte activation. ${ }^{22}$ T-cells and monocytes play an integral role in the regulation of the inflammatory process. One would question whether decreasing T-cell and monocyte activation is appropriate, or if it is merely postponing their work. Juxtaposing this to the theoretical use of cryotherapy, is it better to have less total tissue damage or the inflammatory process occurring naturally and in a timely manner? Many questions remain unanswered such as how long does cryotherapy delay these natural processes, and is that delay detrimental to total healing time?

The second position focuses on the inconclusive and negative literature regarding cryotherapy. A systematic review in the American Journal of Sports Medicine concentrating on acute soft-tissue injury concluded that insufficient evidence exists to 
support the use of ice. ${ }^{23}$ Hubbard and Denegar elaborate further to state "the exact effect of cryotherapy on more frequently treated acute injuries has not been fully elucidated." ${ }^{24}$ Costello, et al. conclude that with regard to $\mathrm{WBC}$, "there is insufficient evidence to determine whether whole-body cryotherapy reduces self-reported muscle soreness, or improves subjective recovery, after exercise compared with passive rest or no WBC in physical active young males." 25 In a separate study, Costello, et al. observed no effect of WBC on indices of muscle damage. $^{26}$

\section{Conclusions}

In today's world of evidence-based medicine, there is little to no evidence for the use of cryotherapy. Nor is there compelling evidence to support the discontinuance of cryotherapy as a therapeutic modality. Many of the studies referred to herein are not strong studies, limited by small sample sizes and/or healthy subjects. Even though scientific evidence is scarce, anecdotal evidence exists. It is not appropriate to base clinical practice on anecdotal evidence, but perhaps this common clinical practice needs to guide future research, with an actual patient population and specific clinical problems and outcomes. The data to substantiate or refute the use of cryotherapy exists in the various settings that use cryotherapy daily and needs to be collected, analyzed, and discussed. In doing so, scientists may be able to answer the questions posed above, amongst others. In the end, it may be determined that beyond providing some minor pain relief, cryotherapy really is of no benefit. Alternately, it could be determined cryotherapy may do all that it is purported to do when used correctly. 


\section{References}

1. Merriam-Webster. Merriam-Webster's Collegiate Dictionary. $11^{\text {th }}$ ed. Springfield, MA:Merriam-Webster, Inc; 2003:640.

2. Knight KL. The effects of hypothermia on inflammation and swelling. Athletic Training. 1976;11:7-10.

3. Knight KL, Draper DO. Therapeutic Modalities: The Art and Science. $2^{\text {nd }}$ ed. Baltimore, MD: Lippincott Williams \& Wilkins; 2013.

4. Merrick MA, Rankin JM, Andres FA, Hinman CL. A preliminary examination of cryotherapy and secondary injury in skeletal muscle. Med Sci Sports Exerc. 1999;31(11):1516-1521.

5. Knight KL. Cryotherapy in Sports Injury Management. Champaign, IL: Human Kinetics, 1995.

6. Starkey, C. Therapeutic Modalities. $4^{\text {th }}$ Ed. Philadelphia, PA: F.A. Davis Company; 2013.

7. LaVelle BE, Snyder M. Differential conduction of cold through barriers. $J$ Adv Nurs. 1985;10(1):55-61.

8. Otte JW, Merrick MA, Ingersoll CD, Cordova ML. Subcutaneous adipose tissue thickness alters cooling time during cryotherapy. Arch Phys Med Rehabil. 2002;83(11):1501-1505.

9. Myrer WJ, Myrer KA, Meason GJ, Fellingham GW, Evers SL. Muscle temperature is affected by overlying adipose tissue when cryotherapy is administered. $J$ Athl Train. 2001;36(1):32-36.

10. Hawkins JR, Miller KC. The importance of target tissue depth in cryotherapy application. $J$ Athl Enhancement. 2012;1:2.

11. Tomchuk D, Rubley MD, Holcomb WR, Giadagmoli M, Tarno JM. The magnitude of tissue cooling during cryotherapy with varied types of compression. $J$ Athl Train. 2010;45(3):230-237.

12. Johannes SM, Knight KL. Temperature response during the warming phase of cryokinetics. 1979.

13. Burke JM, Herman AR, Long BC, Miller KC. Ankle Skin Temperature Changes Following Ice Bag Application with Compression at Varying Levels of Elevation. Athl Train Sport Health Care. 2017; DOI: 10.3928/1942586420170313-02.

14. Hopkins JT, Stencil R. Ankle Cryotherapy Facilitates Soleus Function. J Orthop Sports Phys Ther. 2002;32(12):622-627.

15. Akehi K, Long BC, Warren AJ, Goad CL. Ankle joint angle and lower leg musculotendinous unit responses to cryotherapy. J Strength Cond Res. 2016;30(9): 2482-2492.

16. Verducci FM. Interval cryotherapy decreases fatigue during repeated weight lifting. J Athl Train. 2000;35(4):422-426.

17. McClure M. Stanford researchers' cooling glove 'better than steroids' - and helps solve physiological mystery, too. Available at: http://news.stanford.edu/2012/08/29/coo ling-glove-research-082912/. Accessed May 26, 2017.

18. Whole Body Cryotherapy (WBC): A "Cool" Trend that Lacks Evidence, 
Poses Risks. Available at: https://www.fda.gov/ForConsumers/Co nsumerUpdates/ucm508739.htm.

Accessed May 29, 2017.

19. Ma SY, Je HD, Jeong JH, Kim HY, Kim HD. Effects of whole-body cryotherapy in the management of adhesive capsulitis of the shoulder. Arch Phys Med Rehabil. 2013;94(1):9-16.

20. Bettoni L, Bonomi FG, Zani V, Manisco L, Indelicato A, Lanteri P, Banfi G, Lombardi G. Effects of 15 consecutive cryotherapy sessions on the clinical output of fibromyalgic patients. Clin Rheumatol. 2013;32(9):1337-1345.

21. Hausswirth C, Louis J, Bieuzen F, Pournot H, Fournier J, Filliard, J, Brisswalter J. Effects of whole-body cryotherapy vs. far-infared vs. passive modalities on recovery from exerciseinduced muscle damage in highlytrained runners. PLOS ONE. 2011;6(12):e27749.

22. Linsay A, Othman MI, Prebble H, Davies S, Gieseg SP. Repetitive cryotherapy attenuates the in vitro and in vivo mononuclear cell activation response. Exp Physiol. 2016;101(7):851-865.

23. Bleakley C, McDonough S, MacAuley D. The use of ice in the treatment of acute soft-tissue injury: A systematic review of randomized controlled trials. Am J Sports Med. 2004;32(1):251-261.

24. Hubbard TJ, Denegar CR. Does Cryotherapy Improve Outcomes With Soft Tissue Injury? $J$ Athl Train. 2004;39(3):278-279.

25. Costello JT, Baker PRA, Minett GM, Bieuzen F, Stewart IB, Bleakley C. Whole-body cryotherapy (extreme cold air exposure) for preventing and treating muscle soreness after exercise in adults. Cochrane Database of Systematic Reviews. 2015;9:Art No:CD010789.

26. Costello JT, Algar LA, Donelly AE. Effects of whole-body cryotherapy ($110{ }^{\circ} \mathrm{C}$ ) on proprioception and indices of muscle damage. Scand J Med Sci Sports. 2012;22(2):190-198. 